\title{
Ukuran mesiodistal dan servikoinsisal gigi insisivus sentralis suku Bugis, Makassar, dan Toraja tidak menunjukkan perbedaan yang bermakna
} Size of mesiodistal and cervicoincisal maxillary central incisors between Buginese, Makassarese, and Torajanese showed no significant difference

\author{
${ }^{1}$ Irene Edith Rieuwpassa, ${ }^{1}$ Nurlindah Hamrun, ${ }^{2}$ Fitrian Riksavianti \\ ${ }^{1}$ Bagian Oral Biologi \\ ${ }^{2}$ Mahasiswa tahapan profesi \\ Fakultas Kedokteran Gigi Universitas Hasanuddin \\ Makassar, Indonesia
}

\begin{abstract}
Every tribe and race has size of tooth mesiodistal and cervicoincisal different from each other. The most obvious difference is the size of the teeth between female and male. This study aimed to determine differences in size of mesiodistal and cervicoincisal maxillary central incisors between male and female of Buginese, Makassarese and Torajanese. The sample consisted of 30 Buginese, 30 Makassarese, and 30 Torajanese aged frem 18-25 years-old. After impression of the upper and lower jaw was taken, and size of mesiodistal and cervicoincisal tooth were measured. After the data were analyzed by t-test and ANOVA test, it appears that males have a larger size than females. Makassarese has the longest mesiodistal size $(8.41 \mathrm{~mm})$, Buginese has the longest cervicoincisal size (9.83 $\mathrm{mm})$, whereas Torajanese has the smallest size of mesiodistal and cervicoincisal among the other tribes. It was concluded that the average sizes of mesiodistal and cervicoincisal of maxillary central incisors showed no significant difference. While there are significant differences in the average size of the mesiodistal and cervicoincisal maxillary central incisors between the males and females, and based on tribe lines.
\end{abstract}

Key words: size of maxillary central incisor mesiodistal, size of maxillary central incisor cervicoincisal, men, women, Buginese, Makassarese, Torajanese

\begin{abstract}
ABSTRAK
Setiap suku dan ras memiliki ukuran mesiodistal dan servikoinsisal gigi yang berbeda antara satu sama lainnya. Yang paling jelas terlihat perbedaan ukuran giginya adalah antara perempuan dan laki-laki. Penelitian ini bertujuan untuk mengetahui perbedaan ukuran mesiodistal dan servikoinsisal gigi insisivus sentralis atas antara laki-laki dan perempuan suku Bugis, Makassar dan Toraja. Sampel terdiri dari 30 orang suku Bugis, 30 orang suku Makassar dan 30 orang suku Toraja yang masing-masing berumur 18-25 tahun. Setelah dilakukan pencetakan rahang atas dan bawah, dilakukan pengukuran mesiodistal dan servikoinsisal gigi. Setelah data dianalisis dengan uji-t dan uji anova, tampak bahwa jenis kelamin laki-laki memiliki ukuran yang lebih besar daripada perempuan. Suku Makassar memiliki ukuran mesiodistal terbesar $(8,41 \mathrm{~mm})$. Suku Bugis memiliki ukuran servikoinsisal terpanjang $(9,83 \mathrm{~mm})$. Sedangkan Suku Toraja memiliki ukuran mesiodistal dan servikoinsisal terkecil diantara semua suku. Disimpulkan bahwa rata-rata ukuran mesiodistal dan servikoinsisal gigi insisivus sentralis atas menunjukkan tidak adanya perbedaan yang signifikan. Sementara perbedaan yang signifikan terdapat pada rata-rata ukuran mesiodistal dan servikoinsisal gigi insisivus sentralis atas antara laki-laki dan perempuan dan berdasarkan suku.
\end{abstract}

Kata kunci: ukuran mesiodistal gigi, ukuran servikoinsisal gigi insisivus sentralis atas, laki-laki, perempuan, suku Bugis, suku Makassar, suku Toraja

Koresponden: Irene Edith Rieuwpassa, Bagian Biologi Oral, Fakultas Kedokteran Gigi, Universitas Hasanuddin, Jl. Perintis Kemerdekaan Km.10, Makassar 90245.E-mail:drgirene@yahoo.com

\section{PENDAHULUAN}

Rasio ukuran gigi merupakan suatu data yang dapatmembuat perkiraan tentang rencana perawatan dan memperkirakan hasil perawatan. Diagnosis dan perawatan maloklusi dalam ortodontik memerlukan pengetahuan yang tepat mengenai ukuran gigi karena oklusi yang stabil tergantung pada ketepatan jarak antartonjol dari gigi.Informasi mengenai ukuran gigi populasi manusia,penting dalam bidang kedokteran gigi, sama seperti bidang pengetahuan lain seperti anatomi dan antropologi.
Ukuran rata-rata serta ciri-ciri gigi, rahang dan wajah yang ideal berguna sebagai alat pembanding untuk mengetahui penyimpangan dari normalitas dan dipakai sebagai panduan untuk menentukan rencana terapikelainan dentomaksilofasial. ${ }^{1}$ Jarak mesiodistal gigi diperlukan dalam ilmu antropologi karena memberi informasi yang berguna mengenai evolusi manusia dengan perubahan teknologi dan diet manusia.Ukuran mesiodistal gigi turut memberikan informasi yang signifikan terhadap masalah biologis danodontologi klinis. ${ }^{2}$ Singh dan Goyal ${ }^{3}$ menyatakan 
ukuran gigi sangat berguna bagi dokter gigi untuk mendiagnosis dan merancang perawatan masalah ruang pada gigi, terutama dalam bidang pedodontik dan ortodontik.

Masyarakat Makassar terdiri atas berbagai suku dan etnik sehingga memberikan variasi pada ukuran dan bentuk gigi. Ukuran gigi yang bervariasi ini tidak hanya penting dalam bidang kedokteran gigi tetapi juga dalam menentukan sexual dimorfisme dalam mengidentifikasi seseorang. Selain itu, dari berbagai data yang diperoleh pada saat identifikasi, menentukan suku bangsa penting dilakukan jika terjadi kecelakaan yang melibatkan berbagai jenis suku, misalnya pada kecelakaan pesawat terbang, kereta api dan penemuan mayat tak dikenal.

Menurut two layer theory,terdapat dua migrasi ras ke Indonesia melalui benua Asia, yaitu ras Austromelanesoid dan ras Mongoloid.Percampuran pertama kali antara ras Austromelanesoid dan ras Mongoloid disebut kelompok Proto Melayu (Melayu Tua). Yang termasuk keturunan kelompok ini adalah suku Toraja (Sulawesi Selatan), suku Sasak (Nusa Tenggara Barat),suku Dayak (Kalimantan Tengah), suku Nias (Sumatera Utara), suku Mentawai, suku Baduy,suku Batak (Sumatera Utara) dan suku Kubu (Sumatera Selatan). Percampuran kedua kali antara Proto Melayu dan ras Mongoloid disebut kelompok Deutro Melayu (Melayu Muda). Yang termasuk keturunan kelompok ini adalah suku Aceh, suku Minangkabau (Sumatera Barat), suku Sunda, suku Jawa, suku Bali, serta suku Bugis dan Makasar.

Suku Bugis merupakan salah satu dari empat suku yang awalnya mendiami Sulawesi Selatan. Seperti yang dilaporkan Yusuf dkk, secara genetik suku ini hampir sama dengan suku yang lain walaupun berbeda secara geografis dan budaya. Suku Bugis mendiami hampir seluruh dataran dan perbukitan sebelah selatan. ${ }^{4}$

Lewat penelitian ini, akan diketahui informasi mengenai perbedaan ukuran mesiodistal dan servikoinsisal insisivus sentralis atas antara laki-laki dan perempuan suku Bugis, Makassar dan Toraja.

\section{BAHAN DAN METODE}

Penelitian observasianalitik dengan pendekatan cross sectional dilakukan karena dapat memberikan gambaran ukuran gigi dan juga hubungan dengan jenis kelamin dan suku. Penelitian dilakukan pada populasi yang memenuhi kriteria sampel yang telah ditentukan,yaitu berusia 18-25 tahun, gigi telah erupsi sempurna, tidak fraktur dan atrisi, tidak terdapat restorasi yang luas,tidak menggunakan jacket crown, tidak ada karies atau komposit yang luas melibatkan permukaan mesial dan distal, tidak adanya kelainan bentukdanukuran gigi, dan bersedia menjadi sampel.

Sampel diambil dari masing-masing ras Proto Melayu (suku Toraja),yaitu masyarakat suku Toraja yang bermukim di kota Makassar dan Kabupaten Tana Toraja dan ras Deutero Melayu (suku Bugis dan Makassar), yaitu masyarakat suku Bugis dan Makassar yang bermukim di kota Makassar, Maros dan Pangkep.Pengambilan sampel dilakukan dengan metode purposive non-random.

Ukuran gigi diketahui dengan cara melakukan pencetakan rahang atas dan rahang bawah dengan menggunakan sendok cetak sediaan dan bahan cetak alginat sehingga diperoleh cetakan negatif. Cetakan dicor dengan menggunakan gips keras sehingga diperoleh model positif rahang atas dan bawah. Selanjutnya jarak mesiodistal diukur diantara titik kontak proksimal gigi dengan gigi tetangganya. Sementara servikoinsisal gigi anterior diukur dari garis servikal sampai puncak insisal.

Hasilyang diperoleh dicatat, kemudian dianalisis perbedaanukuran mesiodistal dan servikoinsisal gigi insisivus sentralis atas antar laki-laki dan perempuan pada suku Bugis, Makassar dan Toraja. Data yang diperoleh dianalisis dengan menggunakan uji-t dan uji Anova melalui program SPSS versi 16.

\section{HASIL}

Penelitian mengenai ukuran mesiodistal dan servikoinsisal insisivus sentralis atas berdasarkan suku danjenis kelamin ini,dilakukan pada 30 sampel per suku, terbagi merata laki-laki dan perempuan.

Tabel 1 Perbedaan ukuran mesiodistal dan servikoinsisal gigi insisivus sentralis rahang atas kiri dan kanan secara keseluruhan dan berdasarkan suku

\begin{tabular}{|c|c|c|c|c|c|c|}
\hline \multirow{3}{*}{ Suku } & \multicolumn{3}{|c|}{ Lebar mesiodistal insisivus sentralis } & \multicolumn{3}{|c|}{ Ukuran servikoinsisal insisivus sentralis } \\
\hline & Kanan & kiri & \multirow{2}{*}{ Nilai $p$} & kanan & kiri & \multirow{2}{*}{ Nilai $p$} \\
\hline & $\pm \mathrm{SD}$ & $\pm \mathrm{SD}$ & & $\pm \mathrm{SD}$ & $\pm \mathrm{SD}$ & \\
\hline Bugis & $8,21 \pm 0,56$ & $8,36 \pm 0,68$ & $0,153 * *$ & $9,83 \pm 1,27$ & $9,51 \pm 1,36$ & $0,016^{*}$ \\
\hline Makassar & $8,41 \pm 0,63$ & $8,35 \pm 0,55$ & $0,526 * *$ & $9,76 \pm 1,39$ & $9,73 \pm 1,27$ & $0,818 * *$ \\
\hline Toraja & $7,95 \pm 0,47$ & $7,93 \pm 0,61$ & $0,873 * *$ & $8,90 \pm 0,94$ & $8,85 \pm 0,85$ & $0,586 * *$ \\
\hline Total & $8,19 \pm 0,58$ & $8,21 \pm 0,64$ & $0,710 * *$ & $9,50 \pm 1,27$ & $9,36 \pm 1,23$ & $0,062 * *$ \\
\hline
\end{tabular}


Tabel 2 Perbedaan ukuran mesiodistal dan servikoinsisal gigi insisivus sentralis kanan rahang atas berdasarkan jenis kelamin dan suku.

\begin{tabular}{|c|c|c|c|c|}
\hline Variabel & $\begin{array}{c}\text { Mesiodistal } \\
\pm \mathrm{SD}\end{array}$ & Nilai $p$ & $\begin{array}{c}\text { Servikoinsisal } \\
\pm \mathrm{SD}\end{array}$ & Nilai $p$ \\
\hline \multicolumn{5}{|l|}{ JenisKelamin } \\
\hline Laki-laki & $8,30 \pm 0,62$ & \multirow{2}{*}{$0,089 * *$} & $10,10 \pm 1,24$ & \multirow{2}{*}{$0,000 *$} \\
\hline Perempuan & $8,08 \pm 0,53$ & & $8,90 \pm 1,00$ & \\
\hline \multicolumn{5}{|l|}{ Suku } \\
\hline Bugis & $8,21 \pm 0,56$ & \multirow{3}{*}{$0,007 * * *$} & $9,83 \pm 1,27$ & \multirow{3}{*}{$0,006^{* *}$} \\
\hline Makassar & $8,41 \pm 0,63$ & & $9,76 \pm 1,39$ & \\
\hline Toraja & $7,95 \pm 0,47$ & & $8,90 \pm 0,94$ & \\
\hline Total & $8,19 \pm 0,58$ & & $9,50 \pm 1,27$ & \\
\hline
\end{tabular}

Tabel 3 Perbedaan ukuran mesiodistal dan servikoinsisal gigi insisivus sentralis kiri rahang atas berdasarkan jenis kelamin dan suku

\begin{tabular}{|c|c|c|c|c|}
\hline \multirow{2}{*}{ Variabel } & Mesiodistal & \multirow{2}{*}{ Nilai p } & Servikoinsisal & \multirow{2}{*}{ Nilai $p$} \\
\hline & $\pm S D$ & & $\pm S D$ & \\
\hline \multicolumn{5}{|l|}{ Jenis Kelamin } \\
\hline Laki-laki & $8,35 \pm 0,66$ & \multirow{2}{*}{$0,040 *$} & $9,88 \pm 1,30$ & \multirow{2}{*}{$0,000^{*}$} \\
\hline Perempuan & $8,07 \pm 0,60$ & & $8,84 \pm 0,89$ & \\
\hline \multicolumn{5}{|l|}{ Suku } \\
\hline Bugis & $8,36 \pm 0,68$ & & $9,51 \pm 1,36$ & \\
\hline Makassar & $8,35 \pm 0,55$ & $0,011 * *$ & $9,73 \pm 1,27$ & $0,014 * *$ \\
\hline Toraja & $7,93 \pm 0,61$ & & $8,85 \pm 0,85$ & \\
\hline Total & $8,21 \pm 0,64$ & & $9,36 \pm 1,23$ & \\
\hline
\end{tabular}

*uji-t sampel independen: $\mathrm{p}<0,05$; bermakna; **uji Anova: $\mathrm{p}<0,05$ : bermakna

\section{PEMBAHASAN}

Rerata ukuran mesiodistal dan servikoinsisal gigi insisivus sentralis atas kanan dan kiri

Tanpa memperhatikan jenis kelamin maupun suku,diperoleh rerata lebar mesiodistal gigi insisivus sentralis kanan dan kiri berturut-turut $8,19 \mathrm{~mm}$ dan $8,22 \mathrm{~mm}$. Adapun rerata ukuran servikoinsisal gigi insisivus sentralis atas kanan dan kiri berturut-turut 9,50 $\mathrm{mm}$ dan 9,36 mm. Dengan demikian ukuran mesiodistal dan servikoinsisal suku Bugis,Makassar dan Toraja lebih kecil dari ukuran rata-rata pada tabel ukuran gigi dalam buku anatomi gigi, yaitu mesiodistal sekitar 8,5 $\mathrm{mm}$ dan servikoinsisal sekitar $10,5 \mathrm{~mm}^{5}$

Ukuran servikoinsisal gigi insisivus sentralis kanan terlihat lebih panjang dari insisivus sentralis kiri; hal tersebut mungkin karena faktor kebiasaan cara menyikat gigi yang membuat gigi pada bagian kiri berukuran lebih pendek.Meskipun hal itu masih memerlukan penelitian dan pengkajian yang lebih dalam, akan tetapi pada ukuran mesiodistal dan servikoinsisal gigi insisivus sentralis atas kanan dan kiri walaupun ukurannya berbeda namun dari hasil uji yang ternyata perbedaan tersebut tidak signifikan $(p=0,710$; tabel 1$)$, sehingga dianggap ukuran gigi pada regio kanan maupun kiri umumnya sama.

\section{Perbedaan ukuran mesiodistal dan servikoinsisal gigi insisivus sentralis atas antara laki-laki dan perempuan}

Hasil pengukuran model studi rahang atas suku Bugis, Makassar dan Toraja menunjukkan rerata ukuran mesiodistal gigi insisivus sentralis rahang atas kanan pada laki-laki lebih besar dibandingkan pada perempuan dengan perbedaan mesiodistal sebesar $0,22 \mathrm{~mm}$ dan perbedaan servikoinsisal sebesar 1,20 $\mathrm{mm}$. Namun dari hasil uji statistik hanya ukuran servikoinsisal gigi insisivus sentralis rahang atas kanan yang berbeda bermakna ( $p=0,000$; tabel 2 ).

Sedangkan pada hasil pengukuran gigi insisivus sentralis rahang atas region kiri diperoleh juga hasil pengukuran mesiodistal dan servikoinsisal yang lebih besar pada laki-laki dibandingkan perempuan dengan dengan selisih rerata mesiodistal sebesar $0,28 \mathrm{~mm}$ dan rerata servikoinsisal sebesar $1,04 \mathrm{~mm}$. Selain itu pada uji statistik anova diperoleh nilai $\mathrm{p}=0,04$ untuk ukuran lebar mesiodistal dan $\mathrm{p}=0,00$ untuk servikoinsisal (tabel 3). Hal tersebut menunjukkan 
terdapat perbedaan lebar mesiodistal dan ukuran servikoinsisal gigi insisivus sentralis atas kiri yang signifikan antara laki-laki dan perempuan.

Hasil penelitian ini sesuai dengan penelitian yang dilakukan oleh beberapa peneliti yang turut mendapatkan nilai rerata ukuran mesiodistal gigi laki-laki lebih besar dibandingkan perempuan pada populasi Swedia,pada gigi permanen dan gigi desidui pada populasi bangsa Perancis Kanada didapatkan perbedaan yang bermakna antara laki-laki dan perempuan. Selain itu,turut didapatkan hasil bahwa hampir keseluruhan ukuran mahkota gigi permanen menunjukkan laki-laki lebih besar dibandingkan perempuan yang perbedaannya antara $2-4 \%{ }^{6,7}$

Kromosom Y merangsang pertumbuhan mahkota gigiterhadap dentin dan email,sedangkan kromosom $\mathrm{X}$ hanya tertumpu pada pembentukan email saja. Bahkan dinyatakan lapisan email dan dentin lakilaki relatif lebih tebal dibanding perempuan yang relatif lebih tipis. ${ }^{8}$

\section{Perbandingan rata-rata ukuran mesiodistal dan servikoinsisal gigi insisivus sentralis atas suku Bugis, Makassar dan Toraja}

Dari hasil pengukuran model studi rahang atas pada suku Makassar, Bugis, dan Toraja didapatkan perbedaan yang signifikan pada rata-rata ukuran mesiodistal dan servikoinsisal gigi insisivus sentralis rahang atas antara suku Bugis,Makassar,dan Toraja pada setiap jenis kelamin. Hasil penelitian (tabel 2) menunjukkan bahwa lebar mesiodistal gigi insisivus sentralis atas kanan suku Makassaryang paling besar dan ukuranservikoinsisal yang paling besar terdapat pada suku Bugis dengan hasil uji Anova diperoleh nilai $\mathrm{p}=0,007$ untuk lebar mesiodistal dan $\mathrm{p}=0,006$ untuk ukuran servikoinsisal. Hal ini menunjukkan terdapat perbedaan ukuran lebar mesiodistal dan servikoinsisal gigi insisivus sentralis rahang atas kanan yang signifikan diantara kelompok suku.

Pada pengukuran gigi insisivus sentralis rahang atas region kiri (tabel 3), suku Bugis memiliki lebar mesiodistal yang paling besar dan suku Makassar memiliki ukuran servikoinsisal yang paling besar. Hasil uji Anova menunjukkan nilai $p=0,011$ untuk lebar mesiodistal dan $\mathrm{p}=0,014$ untuk rerata ukuran servikoinsisal. Dengan demikian, disimpulkan ada perbedaan yang signifikan pada ukuran mesiodistal dan servikoinsisal rahang atas kiri antara suku Bugis, Makassar, dan Toraja.

Dari hasil pengukuran dapat dilihat bahwa suku Bugis dan Makassar memiliki rata-rata ukuran yang hampir sama, sementara suku Toraja memiliki nilai rata-rata yang jauh berbeda. Hal tersebut mungkin disebabkan adanya perbedaan ras dari ketiga suku, yaitu suku Toraja berasal dari kelompok Proto Melayu,sementara suku Bugis dan Makassar berasal dari kelompok Deutro Melayu.

Dari hasil penelitian mengenai perbedaan ukuran mesiodistal dan servikoinaisal gigi insisivus sentralis rahang atas antara laki-laki dan perempuan suku Bugis,Makassar,dan Toraja,disimpulkanbahwa rata-rata ukuran mesiodistal dan servikoinsisal gigi insisivus sentralis atas baik kanan maupun kiri menunjukkan tidak ada perbedaan yang bermakna. Akan tetapi perbedaan yang bermakna terdapat pada rerata ukuran mesiodistal gigi dan rerata ukuran servikoinsisal gigi insisivus sentralis atas antara laki-laki dan perempuan, dan berdasarkan suku.

\section{DAFTAR PUSTAKA}

1. Mieke Sylvia MAR. Variasi normal ukuran gigi, rahang dan wajah penduduk pulau Flores dan Timor Nusa Tenggara Timur. Majalah Ilmiah Kedokteran Gigi, Edisi Foril IV 1993: 460-7.

2. Susan N, Al-Khateeb, Elham SJ, Alhaija A. Tooth size discrepancies and arch parameters among different malocclusions in a Jordanian sample. Angle Orthodont 2006; 76 (3): 459-65.

3. Singh SP, Goyal A. Mesiodistal crown dimensions of the permanent dentition in North Indian children. J Indian Soc Pedod Prev Dent 2006;24:192-6.

4. Thalib B. Analisis hubungan status gigi dengan pola makan dan asupan nutrisi pada manula suku Bugis dan suku Mandar. J Dentofasial 2008; 7 (1): 26-37.

5. Itjiningsih WH. Anatomi gigi. Jakarta: Penerbit Buku Kedokteran EGC; 1995. p.101.

6. Suazo GI. Sexual dimorphism in the foramen magnum dimensions. Int J Morphol 2009; 27(1): 21-3.

7. Koesoemahardja HD. Peran genetik pada kelainan dentofasial. Majalah Ilmiah Kedokteran Gigi 2005; Mei: 89-93.

8. Al-Kofide E, Al-Kawari H, Al-Barakati S, Al-Balbeesi H. Orthodontic practical manual. King Saud University. p.15 